\title{
Nghiên cứu ảnh hưởng của điều kiện tách chiết đến hiệu quả thu nhận hoạt chất cordycepin từ nhộng trùng thảo (Cordyceps militaris Linn. Link)
}

\section{Study on the effects of extraction conditions on the extraction efficiency of cordycepin from Cordycep militaris Linn. Link}

\author{
Đoàn Thị Phương Thùy ${ }^{1 *}$, Trần Thị Ngọc Ánh ${ }^{1}$, Nguyễn Thị Mai $^{1}$ \\ ${ }^{1}$ Trường Đại học Nông Lâm Thành phố Hồ Chí Minh, Việt Nam \\ *Tác giả liên hệ, Email: thuydoan@hcmuaf.edu.vn
}

\begin{tabular}{|c|c|}
\hline THÔNG TIN & TÓM TẮT \\
\hline $\begin{array}{l}\text { DOI:10.46223/HCMCOUJS. } \\
\text { tech.vi.13.1.795.2018 }\end{array}$ & $\begin{array}{l}\text { Nhộng Trùng Thảo (Cordyceps militaris Linn. Link) là nấm } \\
\text { có nhiều hoạt chất có giá trị dược liệu cao. Trong số đó, } \\
\text { cordycepin là thành phần quan trọng quyết định chất lượng và }\end{array}$ \\
\hline Ngày nhận: 15/05/2018 & giá trị dược học của Nhộng Trùng Thảo (NTT). Trong nghiên \\
\hline Ngày nhận lại: 07/06/2018 & $\begin{array}{l}\text { cứu này, chúng tôi thực hiện các thí nghiệm đê tìm hiêu ảnh } \\
\text { hưởng của các yếu tố như loai dung môi, tỉ lê dung môi thời gian }\end{array}$ \\
\hline Duyệt đăng: 10/07/2018 & $\begin{array}{l}\text { ủ có đánh sóng siêu âm, độ } \mathrm{pH} \text { của dung môi, nhiệt độ ủ đến hiệu } \\
\text { suất tách chiết hoạt chất cordycepin trong các lượt tách chiết } \\
\text { cordycepin từ quả thể nấm NTT. Kết quả thí nghiệm cho thấy, sự }\end{array}$ \\
\hline Tù khóa: & \\
\hline \multirow[t]{3}{*}{$\begin{array}{l}\text { Cordyceps militaris, } \\
\text { Cordycepin, quả thê, tách } \\
\text { chiết }\end{array}$} & $\begin{array}{l}\text { độ } 55^{\circ} \mathrm{C} \text { có kết hợp đánh sóng siêu âm } 2 \text { lần, mồi lần } 3 \text { phút; } \\
\text { vortex trong } 1 \text { phút và nghỉ } 3 \text { phút giữa hai lần đánh sóng. }\end{array}$ \\
\hline & ABSTRACT \\
\hline & $\begin{array}{l}\text { Cordyceps militaris Linn. Link is a fungus with high content } \\
\text { of bioactive substances. Cordycepin is an important ingredient } \\
\text { that determines the medicinal quality of Cordyceps sp. In this } \\
\text { report, we studied the effects of solvents (type of solvents and } \\
\text { solvent: water ratio), temperature, } \mathrm{pH} \text {, incubation time with } \\
\text { ultrasonication and number of extraction round on the extraction } \\
\text { effiency of cordycepin from Cordyceps militaris fruiting bodies. } \\
\text { Our results showed that, highest extraction efficiency achieved }\end{array}$ \\
\hline Keywords: & \\
\hline $\begin{array}{l}\text { Cordyceps militaris, } \\
\text { Cordycepin, extraction, } \\
\text { fruiting bodies }\end{array}$ & $\begin{array}{l}\text { was at } 55^{\circ} \mathrm{C} \text {. Furthermore, the samples should be ultrasonicated } \\
\text { for } 6 \text { minutes with } 2 \text { pulses of } 3 \text { minutes, vortex for } 1 \text { min and } 3 \\
\text { mins rest between pulses. }\end{array}$ \\
\hline
\end{tabular}




\section{Mở đầu}

Nhộng Trùng Thảo (NTT) (Cordyceps militaris) thuộc ngành Nấm túi (Ascomycota), đây là nhóm Nấm dược liệu có giá trị kinh tế cao và được sử dụng hàng ngàn năm qua trong $\mathrm{y}$ học cổ truyền ở nhiều nước châu Á. Những năm gần đây, khoa học hiện đại cũng đã công bố nhiều nghiên cứu về thành phần dược chất của NTT giá trị dược học và cơ chế tác động của các chất này ở cả mức độ phân tử, tế bào và lâm sàng (Paterson \& Russell, 2008; Tuli, Sharma, Sandhu, \& Kashyap, 2013). Trong các thành phần dược chất của NTT, cordycepin (Hình 1) là dược chất quan trọng quyết định giá trị dược học của NTT, do đó hàm lượng cordycepin là chỉ tiêu tiên quyết để đánh giá chất lượng của NTT (Das Shonkor, Masuda, Sakurai, \& Sakakibara, 2010; Duong \& Le, 2015; Yoo et al., 2004).

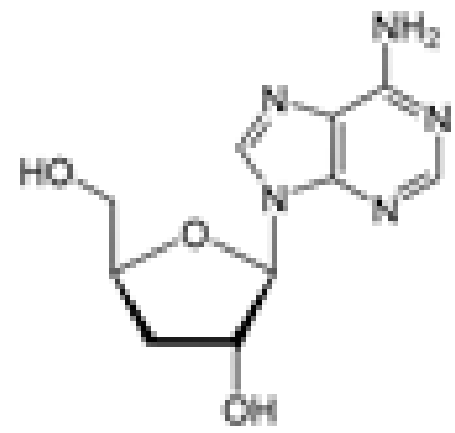

Hình 1. Cấu trúc hóa học của phân tử cordycepin

Trong phần lớn các nghiên cứu, cordycepin được tách chiết bằng dung môi ethanol: nước, 1:1 (v/v); nước nóng (Duong \& Le, 2015; Zhang, Wang, Dong, Xu, \& Wang, 2011); methanol 100\%; methanol: nước, 1:1 (v/v) (Huang, Li, Chen, Wang, \& Zhou, 2009; Reis et al., 2013 ) cùng với sự hỗ trợ của các yếu tố như nhiệt độ, thời gian tách chiết trong quy trình. Tuy nhiên chưa có các báo cáo phân tích, so sánh ảnh hưởng, vai trò của các yếu tố tách chiết đến hiệu quả tách chiết cordycepin.

Trong nghiên cứu này, chúng tôi thực hiện các thí nghiệm tìm hiểu ảnh hưởng của các dung môi thường được sử dụng trong chiết xuất các hợp chất hữu cơ có dược tính như ethanol, methanol, isopropanol và n-butanol trong điều kiện có kết hợp hoặc không kết hợp với nước đến hiệu suất tách chiết cordycepin. Đồng thời các thí nghiệm về ảnh hưởng của thời gian ủ có đánh sóng siêu âm, độ $\mathrm{pH}$, nhiệt độ ủ của dung môi và hiệu suất tách chiết hoạt chất cordycepin trong các lượt tách chiết cũng được thực hiện và đánh giá.

\section{Vật liệu và phương pháp}

\subsection{Anh hưởng của loại dung môi đến hiệu quả tách chiết cordycepin}

Trong thí nghiệm này, hiệu quả tách chiết cordycepin của các dung môi tách chiết có độ phân cực khác nhau được đánh giá. Các dung môi được sử dụng gồm nước, ethanol, methanol, isopropanol và $n$-butanol.

Để thực hiện thí nghiệm, 100mg bột quả thể (Cordyceps militaris giống NBRC 9787, Nhật Bản được nuôi cấy bởi AP Biotech, Việt Nam) được ly trích trong $3 \mathrm{ml}$ dung môi. Các mẫu ly trích được ủ 5 phút trong dung môi ở nhiệt độ phòng, sau đó thực hiện đánh sóng siêu 
âm trong bể rửa siêu âm (Elma $\mathrm{S} 10 \mathrm{H}$, Đức) 2 lần mỗi lần 3 phút, mẫu được vortex trong 1 phút và nghỉ 3 phút giữa các lần đánh sóng.

Mẫu ly trích sau đó được vortex trong 2 phút và ly tâm ở $3500 g$ trong 10 phút để thu nhận dịch nổi cho các phân tích đánh giá hàm lượng cordycepin bằng phương pháp Digital Enhanced - Thin Layer Chromatography (DE-TLC) (Abou-Donia, Darwish, Toaima, Shawky, \& Takla, 2014; Johnsson, Träff, Sundén, \& Ellervik, 2007).

\subsection{Anh hưởng của thời gian đánh sóng siêu âm đến hiệu quả tách chiết cordycepin}

100mg bột sinh khối quả thể nấm được ủ 5 phút trong $3 \mathrm{ml}$ dung môi ethanol: nước, 2:1 (v/v). Hiệu quả tách chiết cordycepin được khảo sát ở các thời gian đánh sóng siêu âm $0,1,3$, 6 và 9 phút. Để tránh làm ảnh hưởng đến cấu trúc của phân tử cordycepin, ở các nghiệm thức đánh sóng 6 và 9 phút, việc đánh sóng được thực hiện theo nhiều đợt, mỗi đợt 3 phút, mẫu được vortex trong 1 phút và nghỉ 3 phút giữa các lần đánh sóng.

Mẫu ly trích sau đó được vortex trong 2 phút và ly tâm ở $3500 \mathrm{~g}$ trong 10 phút để thu nhận dịch nổi cho các phân tích đánh giá hàm lượng cordycepin bằng phương pháp DE-TLC (Abou-Donia et al., 2014; Johnsson et al., 2007).

\section{3. Ảnh hưởng của pH dung môi đến hiệu quả tách chiết cordycepin}

$100 \mathrm{mg}$ bột sinh khối quả thể nấm được ủ 5 phút ở nhiệt độ phòng trong $3 \mathrm{ml}$ dung môi

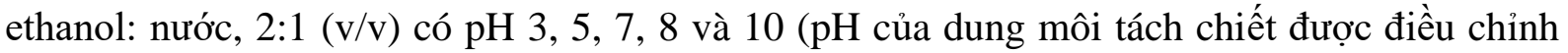
bằng $1 \mathrm{~N} \mathrm{HCl}$ hoặc $1 \mathrm{~N} \mathrm{NaOH}$ ). Sau đó, các mẫu ly trích được đặt trong bể rửa siêu âm và thực hiện đánh sóng trong 2 lần mỗi lần 3 phút, được vortex trong 1 phút và nghỉ 3 phút giữa các lần đánh sóng.

Mẫu ly trích sau đó được vortex trong 2 phút và ly tâm ở $3500 \mathrm{~g}$ trong 10 phút để thu nhận dịch nổi cho các phân tích đánh giá hàm lượng cordycepin bằng phương pháp DE-TLC (Abou-Donia et al., 2014; Johnsson et al., 2007).

\section{4. Ảnh hưởng của nhiệt độ ly trích đến hiệu quả tách chiết cordycepin}

$100 \mathrm{mg}$ bột sinh khối quả thể nấm được ủ 5 phút trong $3 \mathrm{ml}$ dung môi ly trích ethanol: nước, $2: 1(\mathrm{v} / \mathrm{v})$. Sau đó, các mẫu ly trích được đặt trong bể rửa siêu âm ở các nhiệt độ 35,45 , $55,65^{\circ} \mathrm{C}$ thực hiện đánh sóng trong 2 lần mỗi lần 3 phút, được vortex trong 1 phút và nghỉ 3 phút giữa các lần đánh sóng.

Mẫu ly trích sau đó được vortex trong 2 phút và ly tâm ở $3500 \mathrm{~g}$ trong 10 phút để thu nhận dịch nổi cho các phân tích đánh giá hàm lượng cordycepin bằng phương pháp DE-TLC (Abou-Donia et al., 2014; Johnsson et al., 2007).

\subsection{Anh hưởng của số lượt ly trích đến hiệu quả tách chiết cordycepin}

100mg bột sinh khối quả thể nấm được ủ 5 phút trong $3 \mathrm{ml}$ dung môi ethanol: nước, 2:1 (v/v). Sau đó, các mẫu ly trích được đặt trong bể rửa siêu âm và thực hiện đánh sóng trong 2 lần mỗi lần 3 phút và nghỉ 3 phút giữa 2 lần đánh sóng. 
Mẫu ly trích sau đó được vortex trong 2 phút và ly tâm ở $3500 \mathrm{~g}$ trong 10 phút để thu nhận dịch nổi cho các phân tích đánh giá hàm lượng cordycepin bằng phương pháp DE-TLC (Abou-Donia et al., 2014; Johnsson et al., 2007).

Mẫu được ly trích lặp lại với cùng quy trình, lượng cordycepin thu nhận được từ các lượt ly trích được ghi nhận. Hiệu quả thu nhận cordycepin được tính dựa trên tỉ lệ giữa lượng cordycepin thu nhận được ở mỗi lượt và tổng lượng cordycepin thu nhận được qua 3 lượt ly trích.

\subsection{Phân tích hàm lựng cordycepin bằng phương pháp DE-TLC}

Cordycepin thu nhận được từ các mẫu ly trích được phân tách bằng sắc ký lớp mỏng (TLC). Trong đó, 201 dịch trích được chấm trên bản sắc ký TLC Silica 60 F254 (Merck, Đức), và phân tách trong dung môi chloroform: methanol: nước, 65:15:1 (v/v/v). Một 1 cordycepin chuẩn (Sigma-Alrich) có nồng độ $0.01 \mathrm{mg} / \mathrm{l}$ được chấm trên các bản sắc ký, lượng cordycepin chuẩn này ngoài vai trò giúp xác định vị trí của cordycepin trên bản sắc ký còn là chất chuẩn ngoài (external standard) cho việc định lượng cordycepin ở các nghiệm thức thí nghiệm. Vị trí của mẫu trên bản sắc ký được xác định dưới đèn UV có bước sóng $254 \mathrm{~nm}$ trong buồng tối. Hình ảnh của mẫu trên bản sắc ký được ghi nhận bằng máy ảnh Sony Cybershot 7.2 mega pixels. Khoảng cách giữa máy ảnh và bản sắc ký luôn được giữ cố định ở $20 \mathrm{~cm}$, máy ảnh được cài đặt để tất cả các ảnh được chụp ở cùng tiêu cự. Sự khác biệt trong hàm lượng cordycepin thu nhận được từ các thí nghiệm được phân tích và so sánh bằng phần mềm JustTLC (Sweday) dựa trên các thông số về mật độ màu và diện tích của vùng mẫu trên hình ảnh bản sắc ký (AbouDonia et al., 2014; Johnsson et al., 2007).

\subsection{Phân tích thống $k \hat{e}$}

Tất cả các nghiệm thức thí nghiệm được lặp lại ba lần. Kết quả được phân tích thống kê bằng phép thử Duncan nhờ chương trình Statistical Program Scientific System (SPSS) phiên bản 16.0 cho Windows. Các số trung bình trong cột với các ký tự khác nhau kèm theo thì khác biệt có ý nghĩa ở mức $\mathrm{P}<0.05$.

\section{Kết quả và thảo luận}

\subsection{Anh hưởng của loại dung môi đến hiệu quả tách chiết cordycepin}

Ở tất cả các loại dung môi được sử dụng, hiệu quả tách chiết đạt thấp nhất khi không có nước trong dung dịch ly trích (dung môi: nước, $3: 0(\mathrm{v} / \mathrm{v})$ ) cho thấy sự hiện diện của nước là cần thiết. Kết quả này tương tự kết quả của Zhang và cộng sự (2011), trong đó ethanol $100 \%$ cho hiệu quả tách chiết cordycepin thấp hơn so với dung môi ethanol: nước, 1:1 (v/v).

Tuy nhiên, khi chỉ có nước là dung môi, hiệu quả tách chiết cordycepin không cao và ngoài cordycepin còn có sự hiện diện của adenosine và chất khác khi phân tích trên bản sắc ký lớp mỏng (Hình 3, Hình 2). Chúng tôi không nhìn thấy được sự hiện diện của cordycepin trên bản sắc ký TLC ở tất cả các thí nghiệm sử dụng $n$-butanol làm dung môi tách chiết.

Cordycepin là phân tử có tính phân cực, với sự hiện diện của nhóm -OH ở vị trí carbon số 2 của đường và các vị trí có nitơ của adenine (Hình 1). Chính vì thế, để ly trích thành công cordycepin cần có sự hiện diện của dung môi phân cực trong dung dịch tách chiết. Tuy nhiên, 
hiệu quả tách chiết còn phụ thuộc vào sự tương tác của dung môi với các thành phần khác của nguyên liệu (Dong, 2008). Vì thế, sự kết hợp giữa các dung môi có độ phân cực khác nhau là cần thiết để làm tăng hiệu quả tách chiết (Mokrani \& Madani, 2016; Spigno, Tramelli, \& De Faveri, 2007).

Các dung môi tách chiết được sử dụng trong thí nghiệm này là những dung môi có độ phân cực giảm dần theo thứ tự nước, ethanol, methanol, isopropanol và $n$-butanol. Khi dung môi hữu cơ là ethanol, hiệu quả tách chiết đạt cao nhất ở tỉ lệ dung môi: nước, 2:1 (v/v). Tuy nhiên, khi sử dụng methanol và isopropanol có độ phân cực thấp hơn, hiệu quả tách chiết đạt cao nhất ở tỉ lệ dung môi: nước, 1:1 (v/v).

Chúng tôi cũng ghi nhận thấy lượng cordycepin thu nhận được ở các nghiệm thức có sử dụng methanol và isopropanol đạt thấp hơn so với nghiệm thức có sử dụng ethanol. Trong số các nghiệm thức có sử dụng methanol và isopropanol, tỉ lệ dung môi: nước $1: 1,(\mathrm{v} / \mathrm{v})$ cho hiệu quả tách chiết cao hơn các tỉ lệ dung môi: nước khác. Huang và cộng sự (2009) đã sử dụng tỉ lệ dung môi methanol: nước, 1:1 (v/v) và Reis và cộng sự (2013) sử dụng methanol 100\% để tách chiết adenosine và cordycepin từ NTT, tuy nhiên đây là dung môi duy nhất được sử dụng trong các nghiên cứu trên và không có các kết quả so sánh hiệu quả tách chiết của các loại và tỉ lệ dung môi.

Các kết quả của chúng tôi cho thấy, có lẽ sự kết hợp giữa nước và các dung môi hữu cơ với các tỉ lệ khác nhau sẽ làm thay đổi độ phân cực của dung môi tách chiết do đó đem lại hiệu quả tách chiết khác nhau. $n$-butanol là dung môi có độ phân cực thấp nhất trong số 5 loại dung môi được sử dụng và việc sử dụng $n$-butanol không đem lại hiệu quả tách chiết cordycepin.

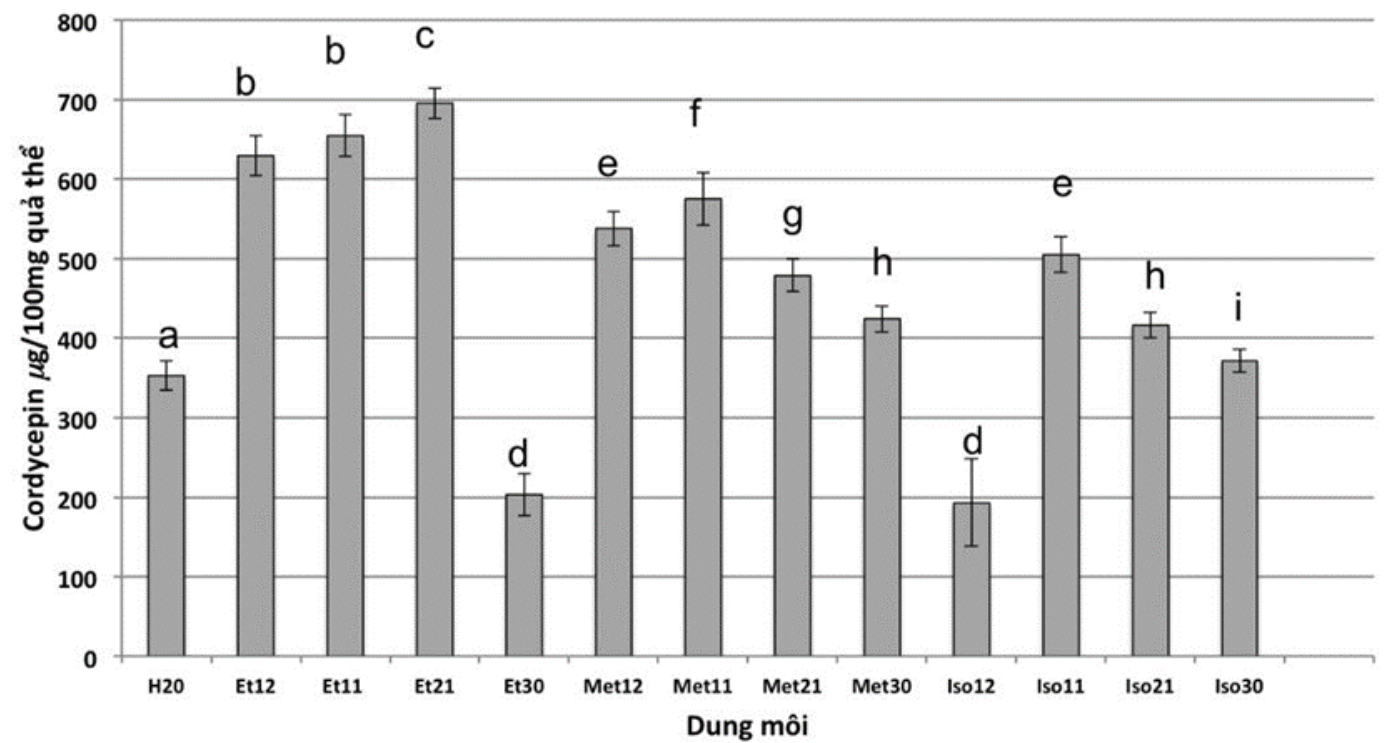

Hình 2. Ảnh hưởng của loại dung môi và tỉ lệ dung môi: nước (v/v) đến lượng cordycepin được tách chiết

Ghi chú: Các chữ viết tắt cho dung môi: Et: Ethanol, Met: methanol, Iso: isopropanol. Các số 11, 12, 21, 30 là các tỉ lệ của dung môi hữu cơ: nước (v/v) trong dung dịch tách chiết. Ví dụ: et12 là tỉ lệ ethanol: nước, 1:2 (v/v) 


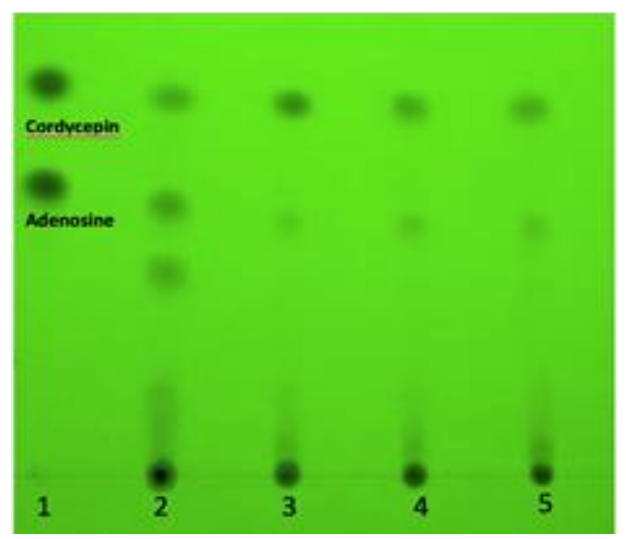

Hình 3. Sự phân tách của mẫu sau tách chiết trên bản sắc ký TLC

Mẫu 1: chất chuẩn

Mẫu 2: mẫu tách chiết trong nước

Mẫu 3: mẫu tách chiết trong ethanol: nước 2:1, (v/v)

Mẫu 4: mẫu tách chiết trong methanol: nước 1:1, (v/v)

Mẫu 5: mẫu tách chiết trong isopropanol: nước 1:1, (v/v)

Vì hiệu quả tách chiết cordycepin đạt cao nhất khi sử dụng dung môi ethanol: nước, 2:1 (v/v) nên chúng tôi sử dụng dung môi này cho các thí nghiệm khảo sát khác.

\section{2. Ảnh hưởng của pH dung môi đến hiệu quả tách chiết cordycepin}

$\mathrm{pH}$ của môi trường có ảnh hưởng lớn đến độ phân cực của chất (Dong, 2008). Trong thí nghiệm của chúng tôi, hiệu suất tách chiết cordycepin đạt thấp nhất ở $\mathrm{pH} 3$ và $\mathrm{pH} 5$, ở $\mathrm{pH} 8$ và pH 10 hiệu suất tách chiết cordycepin cao hơn. Tuy nhiên, hiệu suất tách chiết cordycepin đạt cao nhất ở pH 7 (Bảng 1). Masuda, Hatashita, Fujihara, Suzuki, và Sakurai (2015) đã thực hiện các thí nghiệm tách chiết cordycepin được sản xuất trong môi trường lỏng khi nuôi cấy NTT theo phương pháp lên men sinh khối trong môi trường lỏng cho thấy, độ hòa tan của cordycepin trong dịch nuôi cấy NTT cao khi sử dụng dung môi tách chiết có $\mathrm{pH}$ acid và base. Có lẽ, khác với vật liệu tách chiết là môi trường lỏng có cordycepin, với vật liệu tách chiết là quả thể nấm, $\mathrm{pH}$ của dung môi không chỉ ảnh hưởng đến sự hòa tan của cordycepin mà còn làm thay đổi sự tương tác của cordycepin với các phân tử khác trong thành phần nguyên liệu và cấu trúc tế bào, cấu trúc mô của nguyên liệu và do đó dung môi tách chiết với pH 7 trong thí nghiệm này có hiệu quả tách chiết cordycepin cao nhất.

\section{Bảng 1}

Ảnh hưởng của $\mathrm{pH}$ dung môi đến lượng cordycepin được tách chiết

\begin{tabular}{cc}
\hline $\mathbf{p H}$ & $\begin{array}{c}\text { Cordycepin } \\
(\boldsymbol{\mu g} / \mathbf{1 0 0} \mathbf{~ m g})\end{array}$ \\
\hline $\mathrm{pH} 3$ & $461.84 \pm 20.41^{\mathrm{a}}$ \\
$\mathrm{pH} 5$ & $452.73 \pm 32.04^{\mathrm{a}}$ \\
$\mathrm{pH} 7$ & $695.75 \pm 13.12^{\mathrm{b}}$ \\
$\mathrm{pH} 8$ & $509.44 \pm 26.23^{\mathrm{c}}$ \\
$\mathrm{pH} 10$ & $519.61 \pm 4.66^{\mathrm{c}}$ \\
\hline
\end{tabular}

Nguồn: Kết quả phân tích dữ liệu của nhóm nghiên cứu 


\section{3. Ảnh hưởng của thời gian đánh sóng siêu âm đến hiệu quả tách chiết cordycepin}

Sự đánh sóng siêu âm hỗ trợ sự phá vỡ tế bào, làm giảm các liên kết hóa học giữa các chất, giúp tăng sự khuyếch tán của chất cần ly trích vào dung môi tách chiết, do đó làm tăng hiệu quả tách chiết (Wu, Lin, \& Chau, 2001). Trong nghiên cứu này, lượng cordycepin tăng dần theo thời gian đánh sóng siêu âm và đạt cao nhất ở 6 phút đánh sóng (Bảng 2). Trong thí nghiệm về ảnh hưởng của sóng siêu âm đến hiệu quả tách chiết, Zhang và cộng sự (2011) đã ghi nhận sự đánh sóng siêu âm trong thời gian 35 phút giúp tăng hiệu quả tách chiết. Huang và cộng sự (2009) cũng đề cập đến việc đánh sóng siêu âm trong quy trình tách chiết. Tuy nhiên, cả hai nghiên cứu đều không ghi nhận ảnh hưởng của thời gian đánh sóng siêu âm đến hiệu suất tách chiết cordycepin từ nguyên liệu.

Các kết quả của chúng tôi cho thấy, sự tăng thời gian đánh sóng siêu âm đến 9 phút không giúp gia tăng lượng cordycepin được tách chiết (Bảng 2).

\section{Bảng 2}

Ảnh hưởng của thời gian ủ có đánh sóng siêu âm đến lượng cordycepin được tách chiết

\begin{tabular}{cc}
\hline Thòi gian & Cordycepin $(\boldsymbol{\mu g} / \mathbf{1 0 0} \mathbf{~ m g})$ \\
\hline 0 phút & $227.11 \pm 32.24^{\mathrm{a}}$ \\
1 phút & $368.17 \pm 29.45^{\mathrm{b}}$ \\
3 phút & $470.69 \pm 50.23^{\mathrm{c}}$ \\
6 phút & $657.75 \pm 30.29^{\mathrm{d}}$ \\
9 phút & $692.89 \pm 47.57^{\mathrm{d}}$ \\
\hline
\end{tabular}

Nguồn: Kết quả phân tích dữ liệu của nhóm nghiên cứu

\subsection{Anh hưởng của nhiệt độ ly trích đến hiệu quả tách chiết cordycepin}

Với hầu hết các hợp chất hữu cơ, sự tăng nhiệt độ ủ đóng vai trò quan trọng giúp tăng độ hòa tan và hệ số khuyếch tán của chất (Mokrani \& Madani, 2016; Spigno et al., 2007). Trong phần lớn các trường hợp tách chiết dược chất, để tránh sự biến tính của hoạt chất, nhiệt độ tách chiết luôn được giới hạn ở khoảng nhiệt độ thấp hơn $60^{\circ} \mathrm{C}$ (Dong, 2008). Chính vì thế, chúng tôi thực hiện các thí nghiệm khảo sát hiệu quả tách chiết cordycepin ở trong khoảng nhiệt độ từ $35-65^{\circ} \mathrm{C}$.

Các kết quả cho thấy, lượng cordycepin thu nhận tăng khi tăng nhiệt độ tách chiết và đạt cao nhất ở nhiệt độ $55^{\circ} \mathrm{C}$ và $65^{\circ} \mathrm{C}$ (Hình 4). Zhang và cộng sự (2011) ghi nhận, hiệu quả tách chiết cordycepin ở $85^{\circ} \mathrm{C}$ cao hơn so với hiệu quả tách chiết ở $25^{\circ} \mathrm{C}$.

Các kết quả khảo sát ảnh hưởng của nhiệt độ đến hiệu quả tách chiết cordycepin cho thấy, không có sự khác biệt có ý nghĩa thống kê khi tăng nhiệt độ tách chiết từ $55^{\circ} \mathrm{C}$ đến $65^{\circ} \mathrm{C}$. Như vậy, nhiệt độ $55^{\circ} \mathrm{C}$ là nhiệt độ tối ưu cho sự tách chiết cordycepin từ quả thể NTT. 


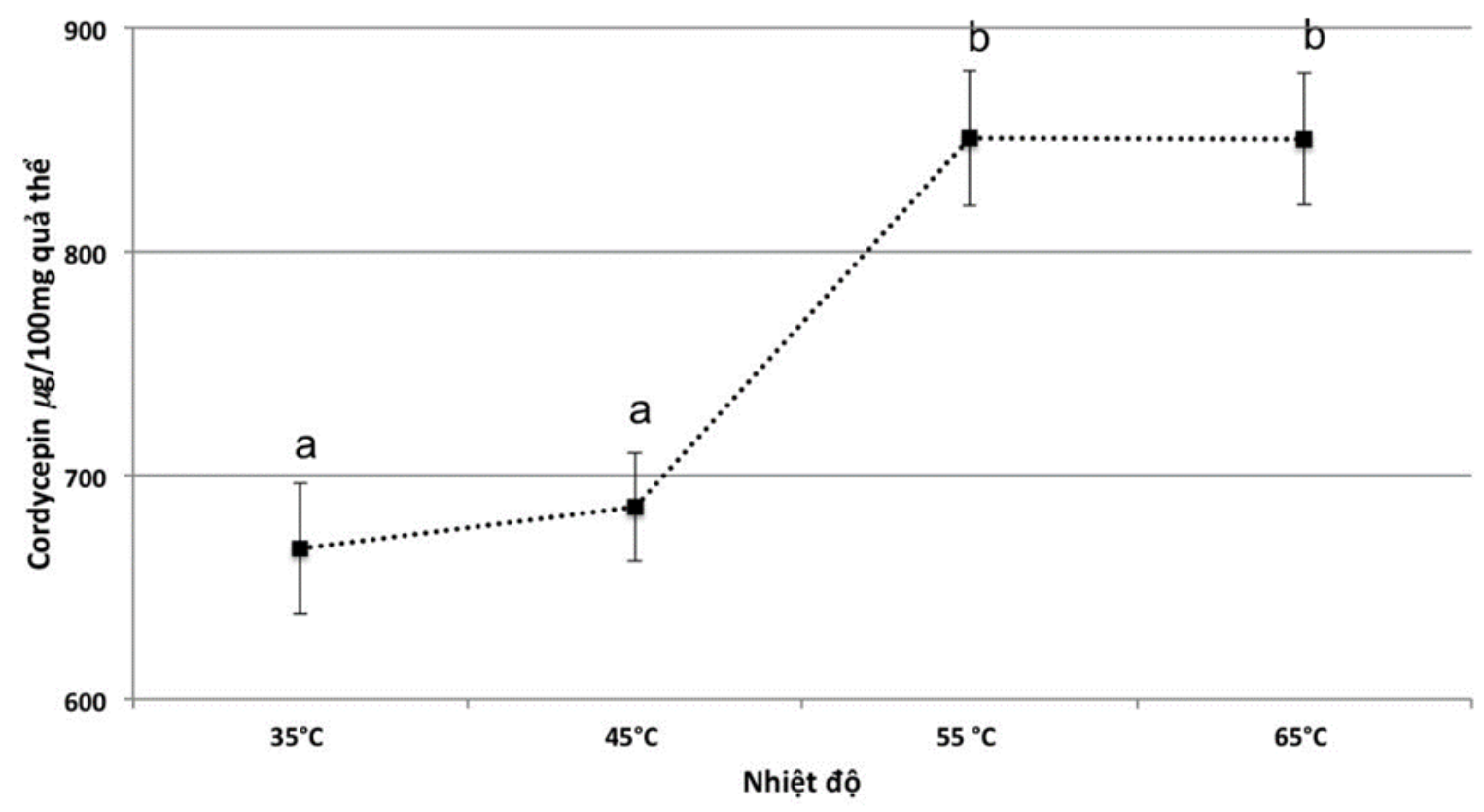

Hình 4. Ảnh hưởng của nhiệt độ ly trích đến lượng cordycepin được tách chiết

\section{5. Ảnh hưởng của số luọt tách chiết đến hiệu quả tách chiết cordycepin}

Để tăng hiệu quả thu nhận chất cần tách chiết, nguyên liệu được ly trích nhiều lượt lặp lại (Duong \& Le, 2015; Wu et al., 2001). Các thí nghiệm tách chiết cordycepin cho thấy, lượt tách chiết đầu tiên cho hiệu quả thu nhận cordycepin đạt $83.79 \pm 2.76 \%$, lượt tách chiết thứ 2 thu nhận được $14.98 \pm 1.22 \%$ cordycepin (Bảng 3). Như vậy, việc lặp lại nhiều lượt tách chiết trên một mẫu là không cần thiết, vì sẽ làm tăng tổng lượng dung môi cần sử dụng và làm loãng nồng độ của cordycepin thu nhận được.

\section{Bảng 3}

Hiệu suất thu nhận cordycepin (\%) sau lượt tách chiết thứ nhất, hai và ba

\begin{tabular}{cc}
\hline Lượt tách chiết & Cordycepin (\%) \\
\hline Lượt 1 & $83.79 \pm 2.76^{\mathrm{a}}$ \\
Lượt 2 & $14.98 \pm 1.22^{\mathrm{b}}$ \\
Lượt 3 & $1.23 \pm 1.54^{\mathrm{c}}$ \\
\hline
\end{tabular}

Nguồn: Kết quả phân tích dữ liệu của nhóm nghiên cứu

\section{Kết luận}

Các thí nghiệm cho thấy, để đạt hiệu quả tách chiết cordycepin cao, mẫu NTT cần được tách chiết với dung môi ethanol: nước, $2: 1(\mathrm{v} / \mathrm{v}) ; \mathrm{pH} 7$; ủ ở nhiệt độ $55^{\circ} \mathrm{C}$ có kết hợp đánh sóng siêu âm 2 lần, mỗi lần 3 phút; vortex 1 phút và nghỉ 3 phút giữa hai lần đánh sóng. 


\section{LỜI CẢM ƠN}

Nghiên cứu được thực hiện nhờ nguồn kinh phí nghiên cứu khoa học cấp cơ sở của Trường Đại học Nông Lâm Thành phố Hồ Chí Minh năm 2016.

\section{Tài liệu tham khảo}

Abou-Donia, A. H., Darwish, F. A., Toaima, S. M., Shawky, E., \& Takla, S. S. (2014). A new approach to develop a standardized method for assessment of acetylcholinesterase inhibitory activity of different extracts using HPTLC and image analysis. Journal of Chromatography B, 955-956, 50-57.

Das Shonkor, K., Masuda, M., Sakurai, A., \& Sakakibara, M. (2010). Medicinal uses of the mushroom Cordyceps militaris: Current state and prospects. Fitoterapia, 81(8), 961-968.

Dong, T. N. (2008). Kỹ thuật chiết xuất dược liệu [Pharmaceutical extraction techniques] . Hanoi, Vietnam: Nhà xuất bản Khoa học và Kỹ thuật.

Duong, T. N., \& Le, T. T. D. (2015). Xây dựng quy trình tối ưu phân tích cordycepin từ hệ sợi nấm đông trùng hạ thảo (Cordyceps militaris) [Develop an optimal process for analyzing cordycepin from cordyceps mycelium (Cordyceps militaris)]. Tạp chi Khoa hoc Kũ thuât Nông Lâm nghiệp, 1, 74-80.

Huang, L., Li, Q., Chen, Y., Wang, X., \& Zhou, X. (2009). Determination and analysis of cordycepin and adenosine in the products of Cordyceps spp. African Journal of Microbiogy Research, 3(12), 957-961.

Johnsson, R., Träff, G., Sundén, M., \& Ellervik, U. (2007). Evaluation of quantitative thin layer chromatography using staining reagents. Journal of Chromatography A, 1164(1), 298305.

Masuda, M., Hatashita, M., Fujihara, S., Suzuki, Y., \& Sakurai, A. (2015). Simple and efficient isolation of cordycepin from culture broth of a Cordyceps militaris mutant. Journal of Bioscience and Bioengineering, 120(6), 732-735.

Mokrani, A., \& Madani, K. (2016). Effect of solvent, time and temperature on the extraction of phenolic compounds and antioxidant capacity of peach (Prunus persica L.) fruit. Separation and Purification Technology, 162, 68-76.

Paterson, R., \& Russell, M. (2008). Cordyceps - A traditional Chinese medicine and another fungal therapeutic biofactory? Phytochemistry, 69(7), 1469-1495.

Reis, F. S., Barros, L., Calhelha, R. C., Ćirić, A., Van Griensven, L. J., Soković, M., \& Ferreira, I. C. (2013). The methanolic extract of Cordyceps militaris (L.) Link fruiting body shows antioxidant, antibacterial, antifungal and antihuman tumor cell lines properties. Food and Chemical Toxicology, 62, 91-98.

Spigno, G., Tramelli, L., \& De Faveri, D. M. (2007). Effects of extraction time, temperature and solvent on concentration and antioxidant activity of grape marc phenolics. Journal of Food Engineering, 81(1), 200-208.

Tuli, H. S., Sharma, A. K., Sandhu, S. S, \& Kashyap, D. (2013). Cordycepin: A bioactive metabolite with therapeutic potential. Life Sciences, 93(23), 863-869. 
Wu, J., Lin, L., \& Chau, F.-T. (2001). Ultrasound-assisted extraction of ginseng saponins from ginseng roots and cultured ginseng cells. Ultrasonics Sonochemistry, 8(4), 347-352.

Yoo, H.-S., Shin, J.-W., Cho, J.-H., Son, C.-G., Lee, Y.-W., Park, S.-Y., \& Cho, C.-K., (2004). Effects of Cordyceps militaris extract on angiogenesis and tumor growth. Acta Pharmacologica Sinica, 25(5), 657-665.

Zhang, H., Wang, J. W., Dong, S. Z., Xu, F. X., \& Wang, S. H. (2011). The optimization of extraction of cordycepin from fruiting body of Cordyceps militaris (L.) Link. Advanced Materials Research, Trans Tech Publications, 393-395, 1024-1028. 